\title{
A SURDEZ, O SURDO E SEU DISCURSO
}

\author{
THE DEAFNESS, THE DEAF AND HIS DISCURSE
}

LA SORDERA, EL SORDO Y SU DISCURSO

\section{Neuma Chaveiro ${ }^{1}$ Maria Alves Barbosa ${ }^{2}$}

\begin{abstract}
RESUMO: O domínio da LIBRAS - Língua Brasileira de Sinais- é determinante no processo de construção das formações discursivas e de constituição dos sujeitos surdos. O presente trabalho tem como objetivo discutir a LIBRAS como ferramenta importante na formação discursiva do indivíduo surdo e como fator facilitador na descrição de seus problemas de saúde. Os dados constituíram se dois textos, sendo um redigido por indivíduo surdo que domina a Língua de Sinais e outro redigido por um surdo que não se expressa por este tipo de linguagem. Verificou-se que o autor do primeiro texto tem coerência, possui mobilidade e circula com facilidade pelas formações discursivas, não ocorrendo o mesmo com o outro surdo. Concluiu-se que a Língua de Sinais é uma ferramenta decisiva na elaboração das formações discursivas dos surdos e a compreensão do seu discurso pelos profissionais da área de saúde propicia maior entendimento da constituição da identidade dos surdos, ponto fundamental para melhor qualidade dos serviços prestados na área de saúde.
\end{abstract}

PALAVRAS CHAVES - Surdez; Comunicação; Linguagem de Sinais.

ABSTRACT: The knowledge of LIBRAS - Brazilian Sign Language - is determining to the process of structuring the discursive formations and to the constitution of the deaf one. The present work aims to discuss the LIBRAS as an important tool of structuring the discursive of the deaf individual an as a facilitating factor in the description of his health problems. The data constitute two texts, one of them wrote by a deaf skilled in LIBRAS and the other wrote by a deaf who does not express himself in this kind of language. It was verified that the first text's author is consistent, has mobility and moves easily through the discursive formations, but otherwise is the text belonging to the other patient. It can be stated that the Brazilian sign language - LIBRAS - is a decisive tool in the working out of the deaf discursive formations and the comprehension of his discourse by the health area professionals provide a larger understanding of the constitution of the deaf identity, a fundamental aspect for an improvement in the services offered in the health area.

KEYWORDS: Deafness; Communication; Sign Language.

RESUMEN: El dominio del LIBRAS - Lenguaje Brasilero de Señales- es determinante en el proceso de construcción de las formas discursivas y de la constitución de los sujetos sordos. El presente trabajo tiene como objetivo discutir el LIBRAS como herramienta importante en la forma discursiva del individuo sordo y como factor de facilitar la descripción de sus problemas de salud. Los datos se constituyeron de dos textos, siendo redactados uno por un individuo sordo que domina el Lenguaje de Señales y el otro por un sordo que no se expresa por este tipo de lenguaje. Se verificó que el autor del primer texto tiene coherencia, posee movilidad y circula con facilidad por las formas discursivas, no ocurriendo lo mismo con el otro sordo. Se concluye que el Lenguaje de Señales es una herramienta decisiva en la elaboración de las formas discursivas de los sordos y la comprensión de su discurso por los profesionales del área de salud propiciando un mayor entendimiento de la constitución de la identidad de los sordos, punto fundamental para la mejor calidad de los servicios prestados en el área de la salud. PALABRAS CLAVE: Sordera; Comunicación; Lenguaje de Señales.

${ }^{1}$ Fonoaudióloga. Centro Estadual de Apoio ao Deficiente - CEAD - Goiânia (GO). Professora Convidada do Departamento de Fonoaudiologia da Universidade Católica de Goiás. $9^{a}$ Avenida, Qd 71; Setor Vila Nova. CEP 74643-080; Goiânia (GO). e-mail neumachaveiro@ig.com.br

${ }^{2}$ Enfermeira. Doutora em Enfermagem. Professora Titular da Faculdade de Enfermagem da Universidade Federal de Goiás. Rua 227, Qd 68 s/n; FEN/UFG. Setor Leste Universitário, CEP 74605-080, Goiânia (GO). mbarbosa@fen.ufg.br 


\section{INTRODUÇÃO}

A língua, oral-auditiva ou espaço-visual, proporciona a comunicação e favorece a organização do pensamento. A surdez afeta o principal meio de comunicação entre as pessoas, inviabilizando o acesso à língua oral-auditiva, logo, a linguagem do surdo temse estruturado através da língua de sinais, que é natural e que possui estruturas próprias diferentes das línguas oralizáveis (FERNANDES, 1998).

A língua de sinais é o canal que os surdos dispõem para receber a herança cultural, e a Língua Brasileira de Sinais LIBRAS é utilizada pela comunidade surda brasileira que se torna diferente das línguas orais, pois, utiliza o canal visual-espacial. É adquirida como língua materna pelas crianças surdas e o simples contato com a comunidade de surdos adultos propicia a sua aquisição naturalmente (BRITO, 1993).

Uma concepção inadequada e muito comum é que a língua de sinais seria universal. $\mathrm{Na}$ verdade, os surdos de diferentes países usam línguas de sinais muito diferentes, além disso, a língua de sinais não é simplesmente uma versão manual da língua oral usada pela comunidade ao redor. Tanto a LIBRAS, quanto a Língua Americana de Sinais (ASL) e a Língua de Sinais Britânica, por exemplo, são mutuamente incompreensíveis. (HICKOK, et al. Edição Especial, s.d. n.04, p. $50-57)$.

Foi imposto, em 1880, no II Congresso Internacional de Educação de Surdos, em Milão, que a comunicação do surdo acontecesse somente na língua oral de seu país, atribuindo à língua de sinais um estatuto de língua inferior, incapaz de expressar conceitos abstratos, sendo superficial e com conteúdo limitado. (SACKS, 1998).

Atualmente as pesquisas envolvendo as línguas de sinais indicam o contrário, referindo que a língua de sinais é um sistema lingüístico altamente estruturado e tão complexo como as línguas faladas, estruturando-se neurologicamente nas mesmas áreas cerebrais das línguas orais.
(HICKOK, et al. Edição Especial, s.d. n.04, p. 50 - 57).

De acordo com o Ministério da Educação do Brasil "as garantias individuais do surdo e o pleno exercício da cidadania alcançaram respaldo institucional decisivo com a Lei Federal $n^{0} 10.436$, de 24 de abril de 2002, em que é reconhecido o estatuto da Língua Brasileira de Sinais como língua oficial da comunidade surda, com implicações para sua divulgação e ensino, para o acesso bilíngüe à informação em ambientes institucionais e para a capacitação dos profissionais que trabalham com os surdos" (BRASIL, 2002, v. 2, p. 62).

Em relação a aquisição da linguagem pelos surdos, observa-se pontos divergentes. Profissionais que trabalham com a filosofia oralista acreditam que a língua de sinais é prejudicial à aquisição da língua oral. A abordagem bilíngüe apresenta uma versão diferente explicitando que a língua de sinais fornecerá todo aparato lingüístico necessário para estruturação do pensamento e aquisição de outras línguas (QUADROS, 1997).

Com as diferentes concepções abrangendo a língua que o surdo utiliza, torna-se pertinente questionar até que ponto dominar ou não a LIBRAS interfere na construção do discurso do surdo.

De acordo com ORLANDI (1999, p. 43) "a formação discursiva se define como aquilo que numa formação ideológica dada determina o que pode e deve ser dito. Por aí podemos perceber que as palavras não têm um sentido nelas mesmas, elas derivam seus sentidos das formações discursivas em que se inscrevem". Para o surdo, ter acesso ou não a LIBRAS, influencia na elaboração das formações discursivas? A LIBRAS possibilita uma maior mobilidade nas formações discursivas?

Segundo ORLANDI (1999, p. 32), "o interdiscurso é todo o conjunto de formulações feitas e já esquecidas que determinam o que dizemos. Para que minhas palavras tenham sentido é preciso que elas já façam sentidos". Como o surdo utilizará o interdiscurso para formular 0 seu intradiscurso? Como se dá a construção de 
todos os dizeres já ditos? Até que ponto a LIBRAS é determinante nesse processo?

O acesso a LIBRAS é primordial na construção da identidade da pessoa surda em todos os seus aspectos, a saber, lingüísticos, cognitivos e social. Exposto a LIBRAS o mais precoce possível, o sujeito surdo teria assim garantido seu direito a uma língua de fato.

Para o profissional de saúde uma efetiva comunicação com seus clientes propicia um atendimento de qualidade, portanto uma formação que vise compreender o sujeito surdo não apenas sua patologia favorece uma assistência humanizada. (BARBOSA et al, 2003)

\section{OBJETIVO}

Discutir a LIBRAS como ferramenta importante na formação discursiva do indivíduo surdo e como fator facilitador na descrição de seus problemas de saúde.

\section{METODOLOGIA}

Pesquisa descritiva realizada no CEAD - Centro Estadual de Apoio ao Deficiente GO.

Os sujeitos do estudo foram dois pacientes, sendo um surdo bilíngüe (L.F.B.) que utiliza a LIBRAS e o Português para comunicação. O outro surdo (S.S.O.) não domina a LIBRAS e comunica-se verbalizando algumas palavras em português e através de sinais criados por ele mesmo.

Ambos estão em acompanhamento fonoaudiológico, visando um adequado desenvolvimento de linguagem.

Foi analisada a escrita dos dois surdos considerando a aquisição da escrita em língua portuguesa como um aprendizado de uma segunda língua, sujeita, portanto, aos erros e dificuldades como qualquer pessoa que esteja aprendendo uma determinada língua estrangeira. $O$ enfoque de análise não foi na construção gramatical, mas no modo como os sujeitos faziam uso da linguagem para produzirem seus enunciados.

Para a coleta de dados foram selecionados dois textos produzidos pelos surdos.

\section{RESULTADOS E DISCUSSÃO}

O estudo realizado permitiu uma reflexão sobre aspectos importantes da constituição do surdo, conhecendo seu discurso percebe-se o sujeito como um todo, e para a área de saúde compreender a linguagem do surdo, é fundamental no seu diagnostico.

Os excertos a seguir, retirados dos textos produzidos pelos sujeitos surdos, referentes à guerra.

O texto I foi elaborado por L.F.B., um adolescente de 13 anos, cursando a $5^{a}$ série do ensino fundamental, apresentando surdez congênita, neurossensorial, profunda e bilateral, em decorrência de rubéola materna. Ele teve a língua de sinais como primeira língua e a língua portuguesa como segunda língua.

"Bush vai guerra, passado prédio alto, avião bateu e derrubou, forte bateu já prédio Bush pensa sim raiva muito, vai guerra... Guerra Iraque contra Estados Unidos (E.U.A.), Estados Unidos forte mais primeira".

Iraque ruim".

"Iraque perdeu já futuro país

mundo!!!"

"E.U.A. primeira rei tudo sabe nada pensa?"

"Iraque perde tudo não sabe

\section{ANÁLISE DO TEXTO I:}

A produção do texto de L.F.B. mostra como a LIBRAS forneceu a base lingüísticocognitiva para o autor se propor como sujeito do seu discurso escrito em português. Utilizando-se do interdiscurso para formular o seu intradiscurso.

Lembrando que L.F.B. domina a LIBRAS, Verifica-se que a sua escrita é dotada de coerência, embora muitas vezes não apresentando certas características formais de coesão, ele consegue expressarse de modo inteligível. As diferenças estruturais entre as línguas de sinais e línguas orais justificam o texto produzido.

O texto II é de autoria de S.S.O., também tem 13 anos, estuda na $4^{\mathrm{a}}$ série do 
ensino fundamental, possui um quadro de surdez neurossensorial, profunda e bilateral, com etiologia desconhecida, segundo a mãe, a surdez foi diagnosticada quando tinha 11 meses, portanto antes da aquisição da linguagem verbal.

"O que gosta não porque tem bomba muito avião eu você não do avião - bomba para porque muito bomba tem eu você não guerra que você fala não Iraque morre muito verdade eu você bomba morre".

\section{ANÁLISE DO TEXTO II:}

No discurso de S.S.O., percebe-se através do texto analisado, que ele praticamente não circula nas teias das formações discursivas, a zona de contato com outras formações discursivas fica restrita, podendo influenciar na constituição de sua identidade frente às imposições da cultura ouvinte.

Percebe-se que L.F.B. tem maior mobilidade e fluidez nas formações discursivas, apresentando multiplicidade de vozes. S.S.O. possui dificuldades para transitar entre as diferentes formações discursivas.

A partir dos resultados obtidos nesta pesquisa, algumas considerações podem ser explicitadas.

A linguagem é um instrumento de poder e aos surdos não pode ser negado o direito de usufruir os benefícios de uma língua, portanto, aceitar a diferença do surdo e conviver com a diversidade humana é um desafio proposto a sociedade. Garantindo ao surdo a aquisição da língua de sinais é possível ver o seu discurso sendo criado na textura de sua língua, como no texto de L.F.B.

Nesse sentido, PIMENTA, ator surdo, diz que: "a surdez deve ser reconhecida como apenas mais um aspecto das infinitas possibilidades da diversidade humana, pois ser Surdo não é melhor ou pior do que ser ouvinte é apenas diferente. Eu nasci Surdo e, como só se perde aquilo que se tem, nunca perdi a audição, pois nunca a tive. Eu tenho direito de viver assim e o mundo tem o dever de aceitar minha diferença" (PIMENTA, 2001, p. 24)

Crianças ouvintes adquirem espontaneamente a linguagem, apesar de crianças ouvintes e surdas aparentemente serem iguais, se a criança surda não for devidamente exposta à aquisição da LIBRAS, torna-se extremamente diferente. Podemos constatar a afirmação no discurso de S.S.O., que não dispondo de um meio de comunicação eficiente, apresenta dificuldades para transitar nas teias das formações discursivas.

Nos textos analisados observa-se que, dominar uma determinada língua, como no caso do surdo L.F.B., significou poder elaborar um discurso usufruindo as vantagens sociais que uma língua proporciona.

$\mathrm{Na}$ área biológica a surdez é relacionada à patologia dando-lhe o caráter de doença a ser tratada. O déficit sensorial nos surdos é real e todos os esforços para evitá-lo e preveni-lo devem ser implementados.

De acordo com BUENO (1999), homogeneizar diferenças de grupos minoritários como, por exemplo, o embranquecimento das populações negras, a eliminação de características como a homossexualidade ou os olhos "puxados" das etnias orientais deve ser evitado, pois representa uma visão incompatível com as diferenças e com a construção da democracia.

Nos casos patológicos, se houver possibilidade de se evitar, prevenir ou solucionar as alterações orgânicas, isto deve ser feito. A perda auditiva existe e dificilmente é reversível, portanto é preciso encontrar formas democráticas de conviver com os surdos.

O vínculo estabelecido entre cliente e profissional de saúde muitas vezes fica prejudicado, pois o cliente é visto como objeto da prática de saúde. Humanizar a assistência em saúde favorece a todos que fazem parte deste processo, incluindo também, o Sistema Único de Saúde, a sociedade brasileira e a cidadania. (BARBOSA et al, 2003) 
O déficit auditivo nos resultados audiológicos é um fato e não se pode deixar de considerá-lo como uma condição intrinsecamente adversa, diferentemente da negritude ou do homossexualismo.

A criança que nasce surda ou se torna surda nos primeiros anos de vida apresenta dificuldades em relação à aquisição de linguagem, sendo este o principal aspecto da surdez, que poderá ocasionar déficit em outras áreas.

As relações sociais acontecem por meio da linguagem, portanto as dificuldades de aquisição da linguagem não são inerentes a pessoa surda, mas decorrem das possibilidades proporcionadas pelo meio social no qual está inserido (GÓES, 1999).

A surdez, de acordo com RUSSO E SANTOS (1989), pode ser definida por um déficit sensorial e sugere a redução ou ausência da capacidade para ouvir determinados sons, devido a fatores que afetam as orelhas externa, média e/ou interna.

As perdas auditivas podem ser classificadas de acordo com o local da lesão, - grau da perda auditiva, época em que ocorreu e a origem. Segundo BESS \& HUMES (1998), as perdas auditivas determinam diminuição da capacidade auditiva em diferentes graus de intensidade, podendo ser de caráter transitório ou definitivo e estacionário ou progressivo. Temos assim surdez congênita, aquelas que ocorreram antes ou durante o nascimento e adquiridas, as que aconteceram após 0 nascimento.

De acordo com RUSSO \& SANTOS (1989), no que se refere ao desenvolvimento de linguagem, surdez congênita é aquela que antecede ao aparecimento das primeiras palavras.

GOLDFELD (1997) acredita que a linguagem é essencial no desenvolvimento da criança surda. Podemos nos perguntar como o surdo se apropria da linguagem no meio que convive, estando afetado por essa privação sensorial. As pesquisas indicam que as línguas espaço-visuais garantem o pleno desenvolvimento do surdo, refletindo, como podemos constatar, nos discursos analisados nesse estudo.
Muito antes de produzirmos qualquer vocalização, de acenarmos com o menor gesto, já estamos imersos nas teias das formações discursivas, num mundo simbolizado: não somos seres da natureza, já nascemos na cultura.

Para conviver com o surdo precisamos aceitar sua língua, sua forma de comunicar e se entrosar com o mundo, não apenas dominar conceitos teóricos referentes a sua patologia. Cabe aos profissionais da saúde uma reflexão mais aprofundada sobre a diversidade reduzindo assim a barreira que os separa.

\section{CONCLUSÃO}

A falta de domínio de uma língua priva o sujeito de participar do burburinho do cotidiano, que vai construindo as várias vozes ao longo do tempo. Ao mesmo tempo a falta de compreensão pelo profissional de saúde quanto à linguagem utilizada pelo sujeito surdo o priva de manifestar suas necessidades.

A relação do sujeito com a língua é que vai produzir a diferença, portanto, o vínculo do surdo com a língua de sinais vai ser determinante, imperioso, essencial, única possibilidade de ele vir a assumir uma posição discursiva que não se reduza à mera reprodução, que permita inferir, modificar, produzir, criar o novo.

A LIBRAS se torna uma ferramenta de empoderamento que permite ao surdo maior mobilidade e fluidez nas formações discursivas, como também fornece subsídios que o ajudam na constituição de suas identidades frentes as imposições (culturais e outras) do ouvinte.

Conclui-se que a língua de sinais é uma ferramenta decisiva na elaboração das formações discursivas dos surdos e a compreensão do seu discurso pelos profissionais da área de saúde propicia um melhor entendimento da constituição da identidade dos surdos, dos sinais e sintomas por eles apresentados, pontos fundamentais para uma melhor qualidade dos serviços prestados. 


\section{REFERÊNCIAS BIBLIOGRAFICAS}

BARBOSA, M.A., OLIVEIRA, M.A., SIQUEIRA, K.M., DAMAS, K.C.A., PRADO, M.A. Linguagem Brasileira de Sinais - Um desafio para a assistência de enfermagem. Rev. de Enfermagem da UERJ. Rio de Janeiro: v.VII, n.03, p. $247-251,2003$.

BESS, F. H. \& HEMES, L. E. Fundamentos de audiologia. 2. ed. Porto Alegre: Artemed, 1998.

BRASIL. Ministério da Educação e Cultura. Ensino de língua portuguesa para surdos, v. 2. Brasília, 2002.

BRITO, L.F. Integração social \& Educação de surdos. Rio de Janeiro: Babel; 1993.

BUENO, J.G.S. Diversidade, deficiência e educação. Rev Espaço - Informativo técnico científico do INES, Rio de Janeiro, n. 12, p. 3 - 12, dez. 1999.

FERNANDES, E. Teorias de Aquisição da linguagem. In: GOLDFELD, M. Fundamentos em fonoaudiologia. Rio de Janeiro: Guanabara Koogan, 1998. p. $1-13$.

GÓES, M.C.R. Linguagem, Surdez e Educação. Campinas: Autores Associados, 1999.
GOLDFELD, M. A Criança Surda: linguagem e cognição numa perspectiva sóciointeracionista. São Paulo: Plexus, 1997.

HICKOK, G. BERLLUGI, U. KLIMA, E. S. A língua de sinais no cérebro. Rev. Scientific American. Brasil: Edição Especial, s.d. n.04, p. $50-57$.

ORLANDI, E. Análise de discurso. Princípios e procedimentos. Campinas: Pontes; 1999. PIMENTA, N. Oficina - Palestra de cultura e diversidade. In: VIII Seminário Nacional do INES. [Anais...] Rio de Janeiro: INES, 2001. QUADROS, R.M. Educação de surdos. A aquisição da linguagem. Porto Alegre: Artes Médicas; 1997.

RUSSO, I.C.P. \& SANTOS, T.M.M. Audiologia infantil. São Paulo: Cortez, 1989. SACKS, O. Vendo Vozes. Tradução de Laura Teixeira Motta. São Paulo: Companhia das Letras; 1998.

Texto recebido em 14/06/2004.

Publicação aprovada em 31/12/2004 